\title{
ESTUDO SOBRE OS CONTRATOS DE ADESÃO AOS PLANOS DE SAÚDE: QUESTIONAMENTO SOBRE O ADEQUADO E EFETIVO ATENDIMENTO AO CONSUMIDOR
}

\author{
Iliane Rodrigues Rego Brasil* \\ Claudete de Souza**
}

\section{RESUMO}

Cuida-se de estudo acerca dos contratos de adesão celebrados para a aquisição de planos privados de assistência à saúde. Esmiuçou-se o tema a partir da relevância jurídica do direito subjetivo à saúde no âmbito do Direito Constitucional, percorrendo os regramentos dos Direitos Civil e Consumerista. Averiguou-se amplo arcabouço normativo atinente ao tema, sob a ótica da Teoria do Diálogo das Fontes (MARQUES, 2016), a fim de analisar a existência de mecanismos legais para a proteção dos direitos e garantias fundamentais do beneficiário, parte vulnerável no negócio jurídico celebradocom a operadora de planos de saúde. Abordamos a Lei de Planos e Seguros de Saúde, sua regulação e especificidades; bem como a estrutura normativa emanada dos Órgãos de Proteção; e tratando da judicialização da saúde privada. Num terceiromomento, indagou-se acerca da eficiência e qualidade na gestão da saúde privada. Com isso, em homenagem ao princípio basilar da dignidade da pessoa humana e aoprincípio da efetiva tutela da saúde, busca-se demonstrar a máxima efetividade do direito à saúde, parte integrante da personalidade jurídica dos indivíduos.

Palavras chave: Planos de Saúde; Direito do Consumidor; Efetiva Tutela da Saúde.

\section{STUDY ON HEALTH INSURANCE ADHERENCE CONTRACTS: QUESTIONING ABOUT ADEQUATEAND EFFECTIVE CUSTOMER SERVICE}

\section{ABSTRACT}

It takes care of a study about the adhesion contracts signed for the acquisition of private health care plans. The theme was explored based on the legal relevance of thesubjective right to health within the scope of Constitutional Law, covering the rules of Civil and Consumer Rights. A broad normative framework related to the theme was investigated, from the perspective of the Theory of the Dialogue of Sources (MARQUES, 2016), in order to analyze the existence of legal mechanisms for the protectionof the fundamental rights and guarantees of the beneficiary, a vulnerable part in the legal business concluded the health plan operator. We address the Health Insurance and Plans

* Bacharel em Direito pela Universidade Metodista de São Paulo. E-mail para contatoilianerb@terra.com.br.

** Doutoranda em Educação. Mestre em Direito. Advogada. Professora Orientadora. E-mail paracontato: claudete.souza@metodista.br 
Law, its regulation and specificities; as well as the normative structure emanating from the Protection Bodies; and dealing with the judicialization of private health. In a third moment, it was asked about the efficiency and quality in themanagement of private health. Thus, in homage to the basic principle of human dignityand the principle of effective protection of health, we seek to demonstrate the maximumeffectiveness of the right to health, an integral part of the legal personality of individuals.

Keywords: Health Plans. Consumer Law. Effective Health Protection.

\section{INTRODUÇÃO}

Os planos e seguros de saúde proporcionam o acesso do beneficiário ao atendimento médico, hospitalar e ambulatorial, mediante contraprestações periódicas, cujas condições e tipos de contratação delimitam a atuação da proponente, ao ser requisitada sua interveniência. Por se tratar de contrato de adesão, espécie contratualem que a operadora estipula unilateralmente o seu teor, caberá ao pretenso beneficiário aderi-lo ou não.

Estudaremos a gestão dos planos de saúde sob o viés jurídico, no que concerne à qualidade dos serviços prestados ao consumidor por todos os atores que compõem a cadeia de saúde privada, analisaremos a natureza dos contratos celebrados para a aquisição de um plano de saúde, bem como verificaremos e traçaremos uma reflexão a despeito da realidade da judicialização da saúde suplementar. Percorreremos tal caminho, a fim de identificar a efetividade jurídica detais contratos, tendo em vista a sua relevância na vida de todos aqueles que optam por arcar com os custos de ter à sua disposição um serviço de saúde privado.

Este artigo está organizado em três seções, quais sejam: 1) $O$ direito fundamental à saúde e os contratos de adesão aos planos privados de assistência à saúde - nesta seção abordamos os aspectos constitucionais, civis e consumeristas atinentes aos planos de saúde, sob o viés da relação contratual celebrada entre beneficiário e operadora, destacando a importância da Teoria do Diálogo das Fontes que, em síntese, trata da possibilidade de aplicação de diversos ramos do Direito às relações oriundas de contratos de planos de saúde; 2) Aincidência da Lei 9.656/1.998 aos planos privados de assistência à saúde e os organismos de proteção ao consumidor - nesta seção tratamos acerca dos planosprivados de assistência à saúde e da criação da ANS, discorremos sobre a importância desta lei e acerca das inovações que ela implantou, bem como acerca dacriação e competências da Agência Nacional de Saúde Suplementar, abordamos também a judicialização da saúde suplementar; 3) Gestão da saúde privada: análiseda eficiência e qualidade dos serviços - nesta seção tratamos da eficiência e qualidade dos serviços prestados pelas operadoras de planos de saúde privada, tendoem vista os contratos celebrados e as determinações da Agência Nacional de Saúde Suplementar.

No decorrer de nossa análise, observaremos que o contrato celebrado entre beneficiário e operadora de plano de saúde, inaugura uma relação privada entre tais partes, porém, apesar de o negócio jurídico celebrado homenagear a autonomia da vontade das partes, há que se observar a vulnerabilidade do consumidor 
diante da força econômica das empresas privadas de saúde, levando-se em conta que os contratos utilizados para a celebração destes negócios são operacionalizados na modalidade de adesão.

O Código de Defesa do Consumidor, em seu artigo $4^{\circ}$, trata da Política Nacional de Relações de Consumo, explicitamente, no inciso I, acerca do "reconhecimento da vulnerabilidade do consumidor no mercado de consumo", sobre a qual discorreremos as especificidades na primeira seção deste artigo, abordando as questões consumeristas, bem como a importância de analisar os negócios jurídicos celebrados à luz do princípio da dignidade da pessoa humana e dos direitos fundamentais dos beneficiários dos planos de saúde privada.

Sendo assim, podemos afirmar que incumbe ao poder público, representado pela Agência Nacional de Saúde Suplementar, pelo Poder Judiciário, pelo Ministério da Saúde, pela ANVISA (Agência Nacional de Vigilância Sanitária), pelo Procon (Programa de Proteção e Defesa do Consumidor), entre outros, dentro da competência que lhes é conferida de fiscalizar, regular, julgar e promover a proteção à saúde.

Fatores sociais, tais como o aumento da expectativa de vida da população e asnovas tecnologias na área da saúde privada, são ensejadores de mudanças no perfildo consumidor, acarretando elevação dos custos operacionais nas carteiras das operadoras, que repassam aos seus clientes os valores que entendem devidos à manutenção do equilíbrio atuarial.

De outro lado, as negativas de atendimento por parte das operadoras de saúde, sob a alegada imprevisão contratual, bem como as cláusulas contratuais consideradasabusivas pela ANS e pelo Poder Judiciário, evidenciam a necessidade de reestruturação da cadeia de saúde suplementar, a fim de se estudarem alternativas que possibilitem o equilíbrio entre as partes.

Destarte, este estudo tem como objetivo precípuo analisar a existência de mecanismos legais para a proteção dos direitos e garantias fundamentais do beneficiário no âmbito dos Direitos Constitucional, Civil e Consumerista, abordando a Lei de Planos e Seguros de Saúde, bem como a análise da judicialização da saúde suplementar.

Ainda, investigar e averiguar os mecanismos disponíveis que possibilitem mensurar a eficiência da gestão das operadoras de saúde e todos os que dela participem, de modo a acautelar o bem maior e indisponível: a saúde do beneficiário dos planos e seguros de saúde privada, por intermédio das medidas legais protetivasacessíveis e em prestígio ao princípio da efetiva tutela da saúde, sagrado no Direito da Saúde Suplementar.

\section{O DIREITO FUNDAMENTAL À SAÚDE E OS CONTRATOS DE ADE- SÃO AOS PLANOS PRIVADOS DEASSISTENNCIA À SAÚDE}

O direito à saúde é tutelado pela Constituição Federal de 1.988 como um direitofundamental inerente a todo e qualquer indivíduo, integrando sua personalidade jurídica e considerado como direito indisponível, amplamente protegido 
pelo ordenamento jurídico pátrio, vez que diretamente relacionado à dignidade da pessoahumana, fundamento da República Federativa e do Estado Democrático de Direito brasileiro.

O artigo $196^{1}$ da Carta Magna esclarece que o direito à saúde é direcionado a todos e dever do Estado, que deve buscar mecanismos de viabilizá-lo. Entretanto, é notório que o sistema público de saúde não está apto a atender todas as necessidadesrelacionadas à saúde dos brasileiros, pelo excesso de demanda e em decorrência daescassez de recursos e de colaboradores.

Diante desse cenário, o setor de saúde suplementar vem crescendo consideravelmente nos últimos anos e, por consequência do aumento da premência,inúmeras questões jurídicas têm se apresentado, mormente no que se refere à efetividade dos serviços prestados aos consumidores. Notamos que os serviços de saúde, sejam eles públicos ou privados, devem observar com afinco os direitos básicos dos seus beneficiários, abrangendo todas as ações necessárias para a prevenção, tratamento e recuperação da doença, bem como para a manutenção e a reabilitação da saúde dos indivíduos.

Como salientado anteriormente, muitas pessoas têm buscado as assistências privadas de saúde, visando o atendimento integral de suas necessidades médicas, hospitalares e laboratoriais, firmando, para tanto, contratos no âmbito do direito privado. Não obstante possuírem natureza de direito privado, os contratos celebrados devem observar todo o regramento constitucional a seu respeito, por tratar de direito fundamental dos beneficiários.

Nesse sentido, Silva (2020, p. 846), esclarece:

As ações e serviços de saúde são de relevância pública, por isso ficaminteiramente sujeitos a regulamentação, fiscalização e controle do Poder Públi$c o$, nos termos da lei, a que cabe executá-los diretamenteou por terceiros, pessoas físicas ou jurídicas de direito privado. Se a Constituição atribui ao Poder Público o controle das ações e serviçosde saúde, significa que sobre tais ações e serviços tem ele integral poder de dominação, que é o sentido do termo controle, mormente quando aparece ao lado da palavra fiscalização. (Grifos do autor)

Em conformidade com o entendimento acima exposto e acerca da importância do direito sob análise, Silveira (2009, p.18), acrescenta que "o direito à saúde está interligado com vários outros direitos, como o do saneamento, o da moradia, o da educação, o do bem-estar social, o da seguridade social, o da assistência social, o de acesso aos serviços médicos e o de saúde física e psíquica".

O contrato de adesão possui natureza enraizada no Direito Civil, observando suas regras e diretrizes de criação dispostas na Teoria Geral dos Contratos. Entretanto, as operadoras de planos de saúde são prestadoras de serviços e possuem

1 Art. 196. A saúde é direito de todos e dever do Estado, garantido mediante políticas sociais e econômicas que visem à redução do risco de doença e de outros agravos e ao acesso universal e igualitário às ações e serviços para sua promoção, proteção e recuperação. 
força econômica, indubitavelmente superior à de seus beneficiários, o que lhesproporciona a proteção sob o manto do Código de Defesa do Consumidor, conforme explicaremos adiante.

Diante de tal cenário, o regulamento e a fiscalização dos contratos de planos privados de assistência à saúde são indispensáveis, conforme destaca Barbugiani (2015, p. 19):

[...] nos planos e seguros de saúde, o objeto do contrato direta e indiretamente relaciona-se com a integridade física e psíquica do indivíduo e de sua família, motivo pelo qual o poder público passou a regular esse tipo de prestação de serviços.

Nesse contexto surgiram instrumentos legais de proteção, como o Código de Defesa do Consumidor (CDC) e a própria Agência Nacionalde Saúde Suplementar (ANS), entretanto eles não são os únicos no Brasil nem se restringem ao nosso país, sendo diversas as formas detutela dos usuários desses serviços ao redor do mundo, variando conforme a política pública adotada por cada Estado.

Dessa forma, nossa pesquisa parte da premissa de vulnerabilidade dosconsumidores de planos de saúde, frente à força econômica das operadoras, bem como em relação ao aumento da adesão aos referidos planos de saúde e o exponencial crescimento da judicialização da saúde suplementar.

Percebemos que os planos de saúde passaram a ser encarados pelosbeneficiários como artigos de primeira necessidade, na busca por uma maior cobertura de atendimentos que satisfaçam suas demandas médicas, hospitalares e laboratoriais. Nesse sentido, Scaff (2010, p. 17) assevera que "a prevenção, manutenção e recuperação da saúde tornaram-se, pois, verdadeiras exigências da sociedade contemporânea, que busca incessantemente viabilizar os meios parasatisfazer tais crescentes necessidades".

Assim, é necessário colocar em pauta a vulnerabilidade dos consumidores dessa espécie de contrato, principalmente no que se refere às negativas de atendimento e aos preços de adesão que se mostram cada vez mais altos, de acordocom a cobertura de atendimentos escolhida pelo aderente. A discussão ganhagrandes contornos no mundo jurídico, uma vez que as questões concernentes à saúdeadquiriram maior importância entre a população, que busca todos os meios possíveis para se resguardar e possuir acesso ao tratamento de eventuais moléstias graves, conforme esclarece Scaff (2010, p. 18-19):

Esses dispêndios cresceram em virtude de uma série de motivos, dentre os quais [...] são a progressiva atenção com os problemas de saúde que dedica hoje a população em geral; o aumento da idade média e da longevidade dos indivíduos, difundindo-se mais amplamente patologias crônico-degenerativas que antes eram menos comuns; além do uso de remédios e de tecnologias sempre mais complexas, que tornam custosa a intervenção terapêutica, seja em virtude da alta tecnologia requerida, seja pela duração dessas mesmas terapias que, em vários casos, não alcançam 
os objetivos pretendidos. Além disso, [...] a noção de doença - reconhecida como uma alteração qualquer do estado normal de saúde - tem sido ampliada nos últimos anos, abrangendo também as consequências de comportamentos sociais que se mostram cada vez mais comuns e que atingem diretamente o equilíbrio biológico dos indivíduos, tais como, por exemplo, a dependência criada pelo uso de tóxicos, o tabagismo, o alcoolismo, o stress provocado pelos modo de vida adotado pelos indivíduos nas sociedades contemporâneas, dentre outras. (Grifos do autor)

Para tanto, faz-se necessário o estudo acerca das espécies de contratos firmados para se adquirir um plano de saúde; bem como sua natureza jurídica e as consequências advindas de sua celebração para os contraentes; além dosorganismos de proteção ao consumidor e a efetiva prestação de serviços comqualidade.

Tal análise é dotada de extrema relevância, pois em razão da crescente demanda e, em função da ampliação da noção de doença, nem sempre as operadoras de planos de saúde conseguem distribuir com equidade e justiça os custos e benefícios entre seus beneficiários, respeitando a noção básica e primordial de que a saúde é um direito de todos e deve, portanto, ser viabilizada de modo a atender as necessidades do indivíduo, sem deixar de observar com cuidado o princípio da dignidade da pessoa humana.

Segundo Gregori $(2019$, p. 20), a prestação de assistência à saúde firmada entre fornecedor e consumidor se dá por meio de um contrato, denominado contrato de plano ou seguro-saúde. [...] contrato de adesão, padronizado, em que todas as cláusulas são preestabelecidas pelo fornecedor.

Vale dizer que as regras contratuais são estipuladas unilateralmente pela operadora, enquanto ao interessado no plano privado de saúde resta apenas aderir, sem poder discutir o conteúdo das cláusulas contratuais, devendo, a partir do início dessa relação contratual de consumo, pagar mensalmente as prestações pecuniárias (prêmio), segundo a segmentação do plano escolhido e o respectivo preço fixo, por tempo indeterminado. Trata-se, portanto, de contrato de adesão, oneroso, de trato sucessivo e aleatório. Em contrapartida, o aderente terá, em evento futuro e incerto, o acesso aos serviços médicos, hospitalares, laboratoriais e odontológicos, segundo

o produto contratado.

O contrato de adesão nada mais é que uma classificação dentre as espécies contratuais e, segundo Diniz (2014, p. 107):

Os contratos por adesão constituem uma oposição à ideia de contratoparitário, por inexistir a liberdade de convenção, visto que excluem a possibilidade de qualquer debate e transigência entre as partes, uma vez que um dos contratantes se limita a aceitar as cláusulas e condições previamenteredigidas e impressas pelo outro, aderindo a uma situação contratual já definida em todos os seus termos. Esses contratos ficam, portanto, ao arbítrioexclusivo de uma das partes - o policitante -, pois o oblato não pode discutirou modificar o teor do contrato ou as suas cláusulas. (Grifo da autora) 
Os contratos de adesão também são conhecidos como contratos de massa, pois redigidos sem sopesar singularidades dos aderentes, mas de forma ampla e geral, impondo suas especificidades de acordo com o determinado pelas prestadorasde serviços, parte mais forte na relação de consumo. Neste sentido, Marques (2016,

p. 73), assevera:

\begin{abstract}
Alguns comparam essa predisposição do texto contratual a um poder paralelo de fazer leis e regulamentos privados (lawmaking power) - poder este que, legitimado pela economia e reconhecido pelo direito acabaria por desequilibrar a sociedade, dividindo os seus indivíduos entre aqueles que detêm a posição negocial de elaboradores da lex privada e os que a ela se submetem, podendo apenas aderir à vontademanifestada pelo outro contratante. (Grifos da autora)
\end{abstract}

Indubitável que o aderente resta em posição desfavorável frente a prestadora de serviços, mormente pela sua superioridade econômica, pela imposição das cláusulas contratuais por meio do contrato de adesão, e pela especialidade técnica necessária para a correta compreensão das cláusulas contratuais de tal espécie de negócio.

Diante de tal situação, o ordenamento jurídico pátrio e as doutrinas clássicascivilista e consumerista, buscam resguardar os direitos básicos dos indivíduos frente ao desequilíbrio contratual que se vislumbra na contratação dos planos privados de assistência à saúde. Acerca do tema e, em relação à necessária interferência do poderpúblico, Barbugiani (2015, p. 20-21) aduz:

(...) a opção dos governantes e dos legisladores (representantes do povo) foi a regulação da prestação de serviço como um todo, sem discriminação de índole econômica dos interessados na adesão ao contrato, estabelecendo um mínimo de serviços que devem ser garantidos pelos planos e seguros de saúde independentemente da vontade das partes, sem prejuízo de coberturas complementares quedemandariam maiores recursos empregados.

Dentro desse contexto, ao contrário do que muitos podem pensar, não se pretendeu priorizar a proteção de uma inferioridade econômica dos beneficiários dos serviços privados de saúde, mas, principalmente, num primeiro momento, a inferioridade jurídica dos aderentes de um contrato em que as disposições são impostas unilateralmente pelas operadoras dos planos e seguros, e, num segundo momento a fragilidade físico-psíquica do indivíduo que ao assinar um contrato desse gênero pode ser influenciado e pressionado por umanecessidade premente do ser humano ligada à sanidade e à tutela dadignidade humana.

Neste diapasão, podemos afirmar ser indispensável a interferência do poder público nas questões jurídicas que envolvem os contratos por adesão, conforme elucida Diniz (2014, p. 107), quando afirma que "consagrada está a ideia de repúdio a quaisquer cláusulas abusivas, iníquas ou desarrazoáveis, por provocarem o desequilíbrio de direitos e deveres, conducentes àquela renúncia antecipada a direitosdo aderente". 
No que concerne aos contratos de planos de saúde, por vezes, as operadoras de saúde privada inserem cláusulas contratuais que afrontam o Código de Defesa doConsumidor, resultando em um grande número de ações judiciais em razão da abusividade de tais cláusulas, estas elencadas nos dezesseis incisos e quatro parágrafos do artigo 51 do referido Diploma.

Há que se observar o direito fundamental constitucional de acesso aosserviços de saúde contratados, bem como a promoção da dignidade da pessoa humana, destacando que todo e qualquer contrato deve ser celebrado de modo a prestigiar os princípios da probidade, da equidade, da boa-fé objetiva, assim como deverá atender a sua função social, conforme elucida Diniz (2014, p. 53):

(...) as partes deverão agir com lealdade, honestidade, honradez, probidade (integridade de caráter), denodo e confiança recíprocas, isto é, proceder com boa-fé, esclarecendo os fatos e o conteúdo nas cláusulas, procurando o equilíbrio das prestações, respeitando o outrocontratante, não traindo a confiança depositada, procurando cooperar,evitando o enriquecimento indevido, não divulgando informações sigilosas etc. É uma norma que requer o comportamento leal e honestodos contratantes, sendo incompatível com quaisquer outras condutasabusivas, tendo por escopo gerar na relação obrigacional a confiançanecessária e o equilíbrio das prestações e da distribuição dos riscos eencargos, ante a proibição do enriquecimento sem causa.

No mesmo sentido, Marques (2016, p. 534) destaca que é importante levar em consideração que "o contrato de seguro trabalha com as expectativas legítimasdos consumidores, que são não só a causa deste, mas a sua garantia e fundamento". Logo, é certo que o indivíduo que busca aderir a um plano privado de assistência à saúde, arcando com o elevado custo desta espécie de contratação, vislumbra ter suas necessidades médicas atendidas, oportunamente, com presteza equalidade, a fim de assegurar a recuperação ou manutenção de sua saúde e de seus familiares, bem como a prevenção de doenças.

Diante das informações postas, é evidente que o beneficiário de um plano de saúde pode ser definido como consumidor, nos termos do artigo $2^{\circ}$ do Código de Defesa do Consumidor (1990), uma vez que utiliza o serviço da operadora como destinatáriofinal; e a prestadora pode ser definida como fornecedora, nos termos do caput do artigo $3^{\circ}$ e $\$ 2^{\circ}$ do referido Diploma, pois presta serviços de natureza securitária.

Enquadrado o beneficiário como consumidor e a operadora como fornecedora, indubitável estarmos diante de uma relação amparada pelos princípios editames do Código de Defesa do Consumidor. Assim sendo, e restando clara a natureza consumerista desta espécie de contrato, passaremos a analisar as consequências advindas desta conclusão.

O Código de Defesa do Consumidor exalta a função social do contrato de consumo, promovendo o equilíbrio contratual, ao amparar os consumidores brasileiros, resguardando seus direitos e garantias, bem como os seus deveres. Com exceção da 
grande parte das tratativas realizadas entre particulares, a maioria dos contratos celebrados, sejam eles solenes e escritos ou informais e tácitos, são dotados da característica de verticalidade em que o prestador do serviço é economicamente superior ao contratante, o que nos leva a tratar da hipossuficiência e da vulnerabilidade destes. Como exemplo dessa realidade, Marques (2016, p. 534-535), destaca:

Muitas práticas e cláusulas presentes no mercado brasileiro de seguros foram consideradas abusivas, em especial a de não renovação desses contratos cativos de longa duração, apesar da previsão expressa do art. $54, \S \S 3^{\circ}$ e $4^{\circ}$, e do Estatuto do Idoso $\left(\operatorname{art.} 15, \S 3^{\circ}\right)$. Outros exemplos são os limites de cobertura, muitas vezes incompatíveis com a finalidade principal do contrato ou mesmo de suadenominação, como no seguro-saúde, as que limitam os tratamentosou exames ou home care e as cláusulas perfil e de agravamento do risco (que devem ser destacadas conforme impõe o art. $\left.54, \S 4^{\circ}\right)$, comoas referentes à embriaguez e terceiro condutor. (Grifo da autora)

Nesse mesmo sentido, posicionamento proferido pelo Superior Tribunal de Justiça, oriundo do Agravo Regimental em Agravo em Recurso Especial, relatado peloMinistro Raul Araújo, no qual este destaca que:

[...] em se tratando de contrato de adesão submetido às regras do CDC, a interpretação de suas cláusulas deve ser feita de maneira mais favorável ao consumidor, bem como devem ser consideradas abusivas as cláusulas que visam a restringir procedimentos médicos.(STJ - AgRg no AREsp: 295133 SP 2013/0033443-9, Relator: MinistroRAUL ARAÚJO, T4 - QUARTA TURMA, Data de Julgamento: 06/06/2013, Data de Publicação: DJe 28/06/2013)

A teor do referido posicionamento, cumpre salientar que o entendimento jurisprudencial tem caminhado no sentido de interpretar os contratos de planos e seguros de saúde reconhecendo sua primordial função social, conforme elucida Marques (2016, p. 536-537):

O seguro tem uma clara dimensão social, em especial nas suas novasmodalidades mais ligadas ao direito à saúde. Mesmo havendo lei sobre os planos de saúde (Lei 9.656/1998), o regime contratual é fortemente influenciado pelas linhas de boa-fé do CDC, que se aplicaem diálogo, o que se comprova pela Súmula 302 do STJ ("É abusiva a cláusula contratual de plano de saúde que limita no tempo a internação hospitalar do segurado") e pela Súmula 469 do STJ: “Aplica-se o Código de Defesa do Consumidor aos contratos de planode saúde". Outro bom exemplo é a continuidade da relação após a despedida do empregado.

Assim, nos contratos de planos de saúde deve-se observar o princípio da boa- fé subjetiva em relação ao beneficiário que se pressupõe, por força de lei, de boa-fé, em razão de sua hipossuficiência e vulnerabilidade. De outra banda, a operadora deve 
primar pelo princípio da boa-fé objetiva, imposta ao fornecedor na integralidade da Lei Consumerista, adotando a conduta de fornecer informações claras, abrangentes, em destaque, prezando cooperação leal e cuidado para com seus beneficiários, a fim de evitar abusos e reequilibrar a relação contratual celebrada por adesão.

Restando esclarecida e justificada a incidência dos regramentos de direito do consumidor aos contratos sob análise, podemos observar a incidência da Teoria do Diálogo das Fontes aos contratos de planos privados de saúde, senão vejamos.

Os contratos de adesão, conforme explanado amplamente, consubstanciam uma espécie de contrato civil, pois se enquadram no conceito de negócio jurídico, além de sua natureza jurídica estar enraizada na noção clássica de prestação de serviços. Entretanto, tais contratos são tutelados pelos regramentos e garantias do Código de Defesa do Consumidor, uma vez que possui uma tutela mais ampla do quea prevista no Código Civil, bem como regulados pela Lei no 9.656/1.998 (Lei dos Planos de Saúde) - normatizada pelas Resoluções e Instruções Normativas oriundasda Agência Nacional de Saúde Suplementar (ANS), que tratam das especificidades da espécie contratual sob análise.

Neste diapasão, tendo em vista o amplo arcabouço normativo atinente ao contrato sob análise, Gomes (2016, p. 91), destaca que:

Cabe ao jurista, portanto, compatibilizar os regramentos específicos dos planos de saúde com as normas civis gerais e as normas consumeristas, de modo a alcançar a unidade do sistema jurídico emprol da adequada e efetiva aplicação ao caso concreto e, principalmente, a concretização do direito fundamental à saúde. Tal compatibilização se torna possível pelo desenvolvimento da Teoria doDiálogo das Fontes, a qual é responsável por promover sempre os direitos fundamentais do sujeito mais frágil da relação posta sob análise.

Neste sentido, vejamos a jurisprudência sobre o tema:

RECURSO ESPECIAL. AÇÃO DE OBRIGAÇÃO DE FAZER C/CCOMPENSAÇÃO DE DANO MORAL. CONTRATO DE PLANO DE SAÚDE COLETIVO POR ADESÃO. RESILIÇÃO UNILATERAL. OPERADORA QUE NÃO COMERCIALIZA PLANO DE SAÚDE INDIVIDUAL E FAMILIAR. CDC. LEI 9.656/1998. ART. $3^{\circ}$ DA RESOLUÇÃO CONSU N ${ }^{\circ}$ 19/1999. DIÁLOGO DAS FONTES. AUSÊNCIA DE NOTIFICAÇÃO PRÉVIA. ABUSIVIDADE. DIREITO À PORTABILIDADE DE CARÊNCIA RECONHECIDO. JULGAMENTO: CPC/15.

1. Ação de obrigação de fazer c/c compensação do dano moralajuizada Em 11/11/2015, da qual foi extraído o presente recurso especial, interposto em 05/02/2018 e atribuído ao gabinete em 11/05/2018.

2. O propósito recursal consiste em decidir sobre a obrigação de a operadora de plano de saúde coletivo por adesão, depois de resilir unilateralmente o contrato firmado com a pessoa jurídica a que estãovinculados os beneficiários, reintegrá-los no mesmo plano, diante da inexistência, em sua carteira de serviços, de plano individual ou familiar, ou adotar outra providência que lhes assegure a 
obtençãoda tutela pelo resultado prático equivalente.

3. A ANS, no exercício de seu poder normativo e regulamentar acerca dos planos de saúde coletivos - ressalvados, apenas, os de autogestão -, deve observar os ditames do CDC.

4. Se, de um lado, a Lei 9.656/1998 e seus regulamentos autorizam a operadora do seguro de saúde coletivo por adesão a não renovar o contrato; de outro lado, o CDC impõe que os respectivos beneficiários, que contribuíram para o plano, não fiquemabsolutamente desamparados, sem que lhes seja dada qualquer outraalternativa para manter a assistência a sua saúde e de seu grupo familiar.

5. A interpretação puramente literal do art. $3^{\circ}$ da Resolução CONSU $n^{0}$ 19/1999 agrava sobremaneira a situação de vulnerabilidade do consumidor que contribuiu para o serviço e favorece o exercício arbitrário, pelas operadoras de seguro de saúde coletivo, do direito de não renovar o contrato celebrado por adesão, o que não tolera o CDC, ao qual estão subordinadas.

6. O diálogo das fontes entre o CDC e a Lei 9.656/1998, com a regulamentação dada pela Resolução CONSU n ${ }^{\circ}$ 19/1999, exige uma interpretação que atenda a ambos os interesses: ao direito da operadora, que pretende se desvincular legitimamente das obrigações zassumidas no contrato celebrado com a estipulante, corresponde o dever de proteção dos consumidores (beneficiários), que contribuíram para o seguro de saúde e cujo interesse é na continuidade do serviço.

7. Na ausência de norma legal expressa que resguarde o consumidor na hipótese de resilição unilateral do contrato coletivo pela operadora, há de se reconhecer o direito à portabilidade de carências, permitindo, assim, que os beneficiários possam contratar um novo plano de saúde, observado o prazo de permanência no anterior, sem o cumprimento de novos períodos de carência ou de cobertura parcial temporária e sem custo adicional pelo exercício do direito.

8. Hipótese em que se reconhece a abusividade da resilição pela operadora do plano de saúde, por inobservância do dever de notificação prévia, e, por conseguinte, a prorrogação dos efeitos do contrato, com a determinação de que os recorrentes sejam devidamente comunicados da extinção do vínculo contratual a fim de que possam exercer o direito de requerer a portabilidade de carência, nos termos da norma regulamentadora.

9. Recurso especial conhecido e parcialmente provido. (STJ - REsp 1739907 / DF, Ministra Nancy Andrighi, T3 - Terceira Turma, Data de julgamento: 18/08/2020, Data de Publicação: DJe - 26/08/2020).

De acordo com Gomes (2016), a Teoria do Diálogo das Fontes nasceu na Alemanha, no ano de 1995, sendo criada pelo professor Erik Jayme, em seu Curso de Direito Internacional, lecionado na Academia de Haia e foi apresentada à doutrina brasileira pela professora Claudia Lima Marques. Tal teoria possui como finalidade precípua a aplicação coordenada de fontes legais conflitantes, a um caso concreto, afim de que a ele seja aplicada a melhor solução jurídica, de modo que seja dada máxima efetividade ao direito que se busca resguardar, conforme elucida Gomes (2016, p. 91-93): 
O objetivo dessa teoria consiste na busca pela convivência e coordenação de fontes normativas diversas potencialmente em conflito, de modo a se impedir a eliminação de qualquer uma dessas normas pela aplicação simultânea e complementar. Assim, há a superação dos critérios clássicos de resolução de antinomias - cronológico, hierárquico e especialidade -, por meio da adoção de umavisão sistemático-constitucional do ordenamento jurídico.

Cumpre salientar que o desenvolvimento da teoria do diálogo das fontes é consequência da visão atual do sistema jurídico, que traduz do Consumidor, Estatuto da Criança e do Adolescente, Estatuto do Idoso -, a pluralidade da sociedade atual. [...] o que ocasiona o pluralismo normativo - com a criação dos microssistemas de normas,por exemplo, Código de Defesa que vem a exigir a necessária construção de uma estrutura de convivência de paradigmas e de métodos, a fim da manutenção da unidade sistêmica.

Destacada a importância da aplicação da Teoria do Diálogo das Fontes aos contratos de planos privados de assistência à saúde em razão da grande variedade normativa incidente, passaremos a tratar da Lei 9.656, de 03 de junho de 1.998, que regulamenta os planos e seguros privados de assistência à saúde.

\section{A INCIDÊNCIA DA LEI 9.656/1.998 AOS PLANOS PRIVADOS DE ASSISTÊNCIA À SAÚDE EOS ORGANISMOS DE PROTEÇÃO AO CONSUMIDOR}

A Lei 9.656/1.998 foi editada para regulamentar o artigo $199^{2}$ da Carta Magna, que autoriza a iniciativa privada a criar assistências de saúde. Sancionada, entrou emvigor após 90 (noventa) dias, conforme se depreende de seu artigo 36. Após a sua sanção, foram editadas 44 (quarenta e quatro) Medidas Provisórias alterando-a, sendo que a primeira destas ocorreu no mesmo dia de sua publicação no Diário Oficialda União. Atualmente, está em vigor a Medida Provisória n ${ }^{\circ}$ 2177-44 de 24 de agostode 2001, por força do artigo $2^{\circ}$ da Emenda Constitucional $n^{\circ} 32 / 01$, que determinou sua vigência por tempo indeterminado até que uma Medida Provisória ulterior a revogue ou por deliberação advinda do Congresso Nacional.

Importante salientar que na redação original, a Lei de planos de saúde, em seu artigo $1^{\circ}$, diferenciava planos e seguros de saúde, sendo tal distinção extinta pela Medida Provisória n ${ }^{\circ}$ 1976-22 de 11 de janeiro de 2000 e mantida pela Medida Provisória $n^{\circ}$ 2177-44/01. Atualmente a Lei trata apenas de planos privados de assistência à saúde, conforme definição emanada da nova redação de seu artigo $1^{\circ}$, inciso I, vejamos:

Art. $1^{\circ}$. Submetem-se às disposições desta Lei as pessoas jurídicas de direito privado que operam planos de assistência à saúde, sem prejuízo do cumprimento da legislação específica que rege a sua atividade,

2 Art. 199. A assistência à saúde é livre à iniciativa privada. 
adotando-se, para fins de aplicação das normas aqui estabelecidas, as seguintes definições:

I - Plano Privado de Assistência à Saúde: prestação continuada de serviços ou cobertura de custos assistenciais a preço pré ou pós estabelecido, por prazo indeterminado, com a finalidade de garantir, sem limite financeiro, a assistência à saúde, pela faculdade de acesso e atendimento por profissionais ou serviçosde saúde, livremente escolhidos, integrantes ou não de rede credenciada, contratada ou referenciada, visando a assistência

médica, hospitalar e odontológica, a ser paga integral ou parcialmente às expensas da operadora contratada, mediante reembolso ou pagamento direto ao prestador, por conta e ordemdo consumidor;

(...) (Grifo nosso)

Acerca da extinta distinção entre planos e seguros de saúde, Marques (2016, p. 545), nos esclarece:

Apesar de a Lei 9.656/1998 nominar os antigos contratos de segurosaúde como planos privados de assistência à saúde, indiscutível que tanto os antigos contratos de seguro-saúde, os atuais planos desaúde, como os - também comuns - contratos de assistência médicapossuem características e, sobretudo, uma finalidade comum: o tratamento e a segurança contra os riscos envolvendo a saúde do consumidor e de sua família e dependentes.

A Lei de Planos de Saúde foi sancionada com a finalidade de regulamentar a contratação, utilização e fiscalização dos planos privados de assistência à saúde. Possui importante papel nesta análise, pois a fim de conferir máxima efetividade aosserviços prestados, limitou a autonomia privada e a liberdade contratual das operadoras, estabelecendo em seu artigo $10 \mathrm{um}$ rol de procedimentos e eventos de saúde que toda operadora de planos privados de assistência à saúde deve, obrigatoriamente, disponibilizar a seus beneficiários.

Esse rol de procedimentos e eventos de saúde também é conhecido como plano de referência de assistência à saúde, com conteúdo e cobertura pré- estabelecidos, conforme disposto no caput do artigo 10, vejamos:

Art. 10. É instituído o plano-referência de assistência à saúde, com cobertura assistencial médico-ambulatorial e hospitalar, compreendendo partos e tratamentos, realizados exclusivamente no Brasil, com padrão de enfermaria, centro de terapia intensiva, ou similar, quando necessária a internação hospitalar, das doenças listadas na Classificação Estatística Internacional de Doenças e Problemas Relacionados com a Saúde, da Organização Mundial de Saúde, respeitadas as exigências mínimas estabelecidas no art. 12 desta Lei (...). (BRASIL, Lei 9.656, 1998)

A Lei de Planos de Saúde dispõe um plano de referência de assistência à saúde, respeitadas as compatibilidades com as segmentações, conceituadas e esmiu- 
çadas no texto do artigo 12, quais sejam: a) plano ambulatorial; b) plano hospitalar; c) plano obstétrico; d) plano odontológico; e, por fim, e) plano completo.

Todos esses segmentos contêm um rol de exigências mínimas de cobertura de procedimentos e eventos de saúde, que devem ser efetivados e devidamente ofertados pela operadora a seus beneficiários, de acordo com a espécie de contratação entre eles celebrada.

No mesmo Diploma, os incisos do artigo 10 apontam um rol de procedimentose eventos de saúde que não são (grifos nossos) de cobertura obrigatória pelas operadoras, os quais deverão ser objeto de regulamentação específica pela agência reguladora (ANS), conforme consignado no $\$ 1^{\circ}$ do artigo 10 . Vejamos:

(...)

I) - Tratamento clínico ou cirúrgico experimental;

II) - Procedimentos clínicos ou cirúrgicos para fins estéticos, bem como órteses e próteses para o mesmo fim;

III) - Inseminação artificial;

IV) - Tratamento de rejuvenescimento ou de emagrecimento comfinalidade estética;

V) - Fornecimento de medicamentos importados não nacionalizados; VI

VI) Fornecimento de medicamentos para tratamento domiciliar,ressalvado o disposto nas alíneas ' $c$ ' do inciso I e ' $\mathrm{g}$ ' do inciso II doart. 12; VII) - Fornecimento de próteses, órteses e seus acessórios não ligadosao ato cirúrgico;

VIII) - Revogado pela Medida Provisória nº 2.177-44, de 2001;

IX) - Tratamentos ilícitos ou antiéticos, assim definidos sob o aspecto médico, ou não reconhecidos pelas autoridades competentes;

X) - Casos de cataclismos, guerras e comoções internas, quando declarados pela autoridade competente. (BRASIL, Lei 9.656, 1998)

Sendo assim, concluímos que a operadora de planos privados de assistência à saúde, independentemente da modalidade e segmento do plano adquirido pelo beneficiário, contará com um rol de procedimentos e eventos de saúde de cobertura obrigatória, consignados por determinação oriunda da Agência Nacional de Saúde Suplementar e de acordo com as normas e diretrizes elaboradas e emanadas da Organização Mundial de Saúde.

Ainda sobre as modalidades de planos de saúde, Martins (2015, p. 203-204), assevera:

O legislador ao dar origem ao plano referência, bem como ao disciplinar as demais modalidades de planos privados de assistência à saúde, acabou por materializar e concretizar o direito fundamental àsaúde no âmbito das relações jurídicas privadas entre operadoras deplanos privados de assistência à saúde e beneficiários, estabelecendouma relação mínima de procedimentos médicos e eventos de saúde de cobertura obrigatória, independentemente da modalidade contratual de plano privado de assistência à saúde celebrada entre osparticulares. Ao disciplinar a obrigatoriedade de uma cobertura mínima, o legislador, no exercício de 
sua atividade de ponderação deinteresses, restringiu a autonomia e liberdade contratuais das operadoras de planos privados de assistência à saúde como forma degarantir a necessária proteção do direito à saúde, contribuindo para aestabilização destas relações jurídicas.

Restando claro os procedimentos e eventos de saúde que devem, obrigatoriamente, ser cobertos e oferecidos aos beneficiários pelas operadoras de planos privados de assistência à saúde, a controvérsia reside acerca dos procedimentos e eventos de saúde não contidos na obrigatoriedade e não previstos contratualmente.

Com a promulgação da Lei de Planos de Saúde, constatou-se a necessidade de criação de uma agência reguladora para o setor de saúde suplementar e, assim, surge a Agência Nacional de Saúde Suplementar (ANS), autarquia criada sob o regime especial, com a finalidade precípua de regular, normatizar, controlar e fiscalizaras atividades exercidas pelos planos de saúde para que seja dada real efetividade aoacesso à saúde dos beneficiários.

Acerca da agência reguladora, Gomes (2016, p. 83-84), consigna:

[...] consiste em autarquia sob o regime especial - o que lhe confere autonomia administrativa, financeira, patrimonial e de gestão de recursos humanos, autonomia nas suas decisões técnicas e mandatofixo de seus dirigentes - vinculada ao Ministério da Saúde, com sedee foro na cidade do Rio de Janeiro/RJ. Prazo de duraçãoindeterminado e atuação em todo o território nacional, como órgão deregulação, normatização, controle e fiscalização das atividades que garantam a assistência suplementar à saúde (art. $1^{\circ}$ da Lei $\left.n^{\circ} 9.961 / 00\right)$. Possui por finalidade institucional promover a defesa do interesse público na assistência à saúde, regulando as operadoras setoriais, inclusive quanto às suas relações com prestadores e consumidores, contribuindo para o desenvolvimento das ações de saúde no País (art. $3^{\circ}$ ).

Cumpre salientar que a ANS não possui o poder de legislar acerca deassuntos relacionados à saúde, pois a Constituição Federal não lhe conferiu tal competência, portanto, possui tão somente o poder de fiscalizar e de normatizar disciplinas já contidas na Lei de Planos de Saúde, com a finalidade precípua de exercer o controle e a fiscalização que lhe são inerentes sobre as operadoras de planos privados de assistência à saúde, conforme previsto na Lei 9.656/1.998.

Sobre as funções da ANS, Barbugiani (2015, p. 87), esclarece:

A Agência Nacional de Saúde Suplementar tem função de fiscalização das atividades das operadoras de planos de saúde privados. Como instrumento de repressão e prevenção de atividades que possam vir acausar prejuízos ao consumidor, a autarquia federal poderá tomar medidas específicas para coibir o abuso e fazer cessar a prática ilegítima, além de eventualmente ajuizar as ações judiciais de índole coletiva, por ser um ente público também legitimado pelo CDC. 
A Lei 9.656/1.998 legisla, em seu artigo 25, acerca das penalidades cabíveis nos casos de infração e descumprimento de suas normas, cuja competência para aplicação é da ANS. As penas contidas neste artigo são: advertência; multa pecuniária; suspensão do exercício do cargo; inabilitação temporária para exercício de cargos em operadoras de planos de assistência à saúde; inabilitação permanente para o exercício de cargos de direção ou em conselhos das operadoras, bem como em entidades de previdência privada, sociedades seguradoras, corretoras de segurose instituições financeiras; por fim, o cancelamento da autorização de funcionamento ealienação da carteira da operadora.

Conforme o caput do artigo sob análise, as penalidades não são restritas apenas às operadoras de planos de saúde, mas podem ser aplicadas e alcançar em responsabilidade solidária os seus administradores, membros de conselhos administrativos, deliberativos, consultivos, fiscais e assemelhados. Ademais, cumpre destacar que é de responsabilidade da ANS toda a regulamentação necessária para a instauração do processo administrativo de sua competência.

Neste diapasão, Barbugiani (2015, p. 89), destaca:

É importante salientar que a ANS possui um poder de fiscalização e apenação em relação às pessoas jurídicas que exercem as atividadesde planos privados de assistência à saúde, entretanto, isso jamais impedirá a competência dos Conselhos Regionais de regências das profissões típicas da saúde, como Medicina, Enfermagem, Farmácia,entre outras, para a aplicação de penalidades aos respectivos profissionais da saúde, pois as instâncias são diferentes e antes de sesobreporem, acabam por se completar, na busca de um serviço de qualidade aos consumidores.

Esclarecidos tais pontos, adentraremos na interferência estatal nas relações formadas nos planos privados de assistência à saúde, a fim de verificar o alcance e a importância dessa interferência no sentido de viabilizar o acesso à saúde dos beneficiários de forma justa e de acordo com os ditames legais. Para tanto, oMinistério Público atuará como fiscal da lei e como ente legitimado a promover a defesa dos direitos dos vulneráveis, nesse caso, os beneficiários dos planos privados de assistência à saúde. Sua legitimidade ativa está prevista no artigo 82, inciso I, do Código de Defesa do Consumidor, ao propor ação civil pública ou ação coletiva para a defesa de direitos difusos, coletivos e individuais homogêneos concernentes à saúde suplementar. Há que se destacar que, quando não figurar como autor de ação,o Ministério Público ainda assim figurará na demanda como custos legis a fim de promover o resguardo do interesse público.

Acerca da importante participação do Ministério Públicos nesses feitos, Barbugiani $(2015$, p. 83$)$, consigna:

O Ministério Público, segundo o CDC, é um dos instrumentos da execução da Política Nacional das Relações de Consumo, tendo o art.5ํㅜ II, da Lei 8.078/1990 estipulado como um desses meios a criação de promotorias especializadas na defesa do consumidor. 
As entidades de defesa dos consumidores e os próprios consumidores podem solicitar ao Ministério Público que analise eventual cláusula presente nos contratos e, na hipótese de verificar afronta ao CDC ou um desequilíbrio entre os direitos e obrigações das partes na relação de consumo, o devido ajuizamento da ação, visando à declaração de sua nulidade, situação muito comum quando se constata a existênciade cláusulas abusivas.

Há que se citar também a importância da Defensoria Pública na proteção aos direitos dos consumidores dos planos de saúde. Inicialmente, destacamos que a suacompetência é concorrente com o Ministério Público para a defesa de interesses e direitos dos beneficiários, de acordo com o disposto na Lei da Ação Civil Pública (Lei

n. 7.347/1.985), em seu artigo $5^{\circ}$, inciso II. Insta salientar, ademais, que sua atuaçãose dará no âmbito da defesa dos consumidores hipossuficientes.

O consumidor também pode recorrer ao Procon e ao Instituto Brasileiro de Defesa ao Consumidor (Idec) para a orientação, consulta, satisfação e cumprimento de seus direitos e garantias relacionados à saúde, sendo certo que o Procon possui poder de polícia e, portanto, competência para a aplicação de multas nos casos em que constatar infração e descumprimento das regras de natureza consumerista.

Entretanto, tais medidas administrativas não se mostram suficientes, considerando que grande parte das demandas são apresentadas ao judiciário, pois somente este órgão detém a competência necessária para determinar de forma coercitiva que a operadora de saúde suplementar dê efetividade ao pedido formuladopelo beneficiário, cumprindo a legislação atinente ao tema.

Neste ínterim, Fabretti (2017, p. 449), aduz:

Contribui para o agravamento da situação o fato de que, na maioria dos casos envolvendo saúde suplementar, há urgência na tutelaprestacional pleiteada, ou, o consumidor não pode aguardar por uma decisão do Procon, que determina a prestação de determinado serviçoe, caso não seja cumprida, ter de recorrer ao Judiciário. Por esse aspecto temporal, no mais das vezes, recorre-se diretamente ao PoderJudiciário, já que neste, sendo concedida a tutela, haverá imposição de multa diária em caso de eventual descumprimento, fato que torna a decisão muito mais efetiva.

Traçados os parâmetros legislativos que contornam e incidem na relação entre operadora e beneficiário do plano privado de saúde, bem como apresentados os agentes representantes do Poder Público e da sociedade civil na defesa dos interesses dos consumidores, há que se acrescentar a atuação do Poder Judiciário nas demandas em que uma determinada operadora de Planos de Saúde é integrantedo polo passivo.

Adentramos, assim, na judicialização do direito à saúde na seara das relações privadas entre beneficiários e operadoras de planos privados de assistência à saúde.Inobstante a existência de todo o arcabouço normativo que regulamenta a relação entre beneficiário e operadora de saúde suplementar, com a presença, inclu- 
sive, de uma agência reguladora, criada a fim de mediar os conflitos oriundos de tal relação, podemos averiguar que todo o respaldo jurídico criado para amparar o beneficiário não tem se mostrado suficiente a ponto de evitar a necessidade de se socorrer do Poder Judiciário para a solução de questões controvertidas.

A judicialização em face da operadora de planos privados de assistência à saúde ocorre pelos mais diversos motivos, entre os mais recorrentes podemos citar: a presença de cláusulas abusivas no contrato de adesão; a negativa de cobertura de procedimentos e eventos de saúde; exclusões ilegais de beneficiários; exclusão de médicos e de estabelecimentos de saúde da rede de atendimento, sem prévio aviso ao consumidor e sem a devida substituição; aumentos abusivos nas mensalidades; negativa de inclusão de pessoa idosa ou com doença preexistente, entre outros.

Sobre a atuação do judiciário no deslinde das ações propostas nesses casos, Fabretti (2017, p. 428-429), leciona:

(...) além de interpretar de forma especial as questões em que o objetoé a saúde do consumidor, há também uma preocupação do Poder Judiciário em prestar uma tutela especial àquele mais vulnerável, tendo em conta as proteções garantidas pela Constituição e pelo Código de Defesa do Consumidor, principalmente em se tratando de contratação por adesão. É possível constatar, portanto, que há uma busca tanto da doutrina como da lei e também do próprio Poder Judiciário, para que a formação e execução dos contratos de consumo, feitos por adesão, nos quais se encaixam os de plano de saúde, sigam os ditames da boa-fé objetiva, punindo abusos e equilibrando as forças na relação contratual.

Nesse sentido, vejamos:

RECURSO ESPECIAL. AÇÃO DE OBRIGAÇÃO DE FAZER. PLANO DE SAÚDE.

CONTRATO COLETIVO POR ADESÃO. FALECIMENTO DO TITULAR. DEPENDENTE IDOSA. PRETENSÃO DE MANUTENÇÃODO BENEFÍCIO. SÚMULA NORMATIVA 13/ANS. NÃO INCIDÊNCIA. ARTS. 30 E 31 DA LEI 9.656/1998.

INTERPRETAÇÃO EXTENSIVA DOS PRECEITOS LEGAIS. CONDIÇÃO DE CONSUMIDOR HIPERVULNERÁVEL. JULGAMENTO: $\mathrm{CPC} / 15$.

1) Ação de obrigação de fazer ajuizada em $27 / 11 / 2017$, da qual foi extraído o presente recurso especial, interposto em 24/09/2019 e atribuído ao gabinete em 17/04/2020.

2) O propósito recursal consiste em decidir sobre a manutenção de dependente em plano de saúde coletivo por adesão, após o falecimento do titular.

3) Há de ser considerado, à luz do disposto na Resolução ANS 195/2009, que, diferentemente dos planos privados de assistência à saúde individual ou familiar, que são de "livre adesão de beneficiários, pessoas naturais, com ou sem grupo familiar" (art.

$3^{\circ}$ ), os planos de saúde coletivos são prestados à população delimitada, vinculada à pessoa jurídica, seja esse vínculo "por relaçãoempregatícia 
ou estatutária" (art. $5^{\circ}$ ), como nos contratos empresariais, seja por relação "de caráter profissional, classista ou setorial" (art. $9^{\circ}$ ), como nos contratos por adesão.

4) É certo e relevante o fato de que a morte do titular do plano de saúde coletivo implica o rompimento do vínculo havido com a pessoa jurídica, vínculo esse cuja existência o ordenamento impõe como condição para a sua contratação, e essa circunstância, que não se verifica noscontratos familiares, impede a interpretação extensiva da súmulanormativa 13/ ANS para aplicá-la aos contratos coletivos.

5) Em se tratando de contratos coletivos por adesão, não há qualquer norma - legal ou administrativa - que regulamente a situação dos dependentes na hipótese de falecimento do titular; no entanto, seguindo as regras de hermenêutica jurídica, aplicam-se-lhes as regras dos arts. 30 e 31 da Lei 9.656/1998, relativos aos contratos coletivos empresariais.

6) Na trilha dessa interpretação extensiva dos preceitos legais, conclui-se que, falecendo o titular do plano de saúde coletivo, seja este empresarial ou por adesão, nasce para os dependentes já inscritos o direito de pleitear a sucessão da titularidade, nos termos dos arts. 30 ou 31 da Lei 9.656/1998, a depender da hipótese, desde que assumamo seu pagamento integral.

7) E, em se tratando de dependente idoso, a interpretação das referidas normas há de ser feita sob as luzes do Estatuto do Idoso (Lei $n^{\circ}$ 10.741/03) e sempre considerando a sua peculiar situação de consumidor hipervulnerável.

8) Recurso especial conhecido e desprovido, com majoração de honorários. (REsp 1871326/RS, Rel. Ministra NANCY ANDRIGHI, TERCEIRA TURMA, julgado em 01/09/2020, DJe 09/09/2020)

É inevitável que, ao apreciar as demandas propostas em face da saúde suplementar, o Judiciário interfira na relação contratual e na autonomia da vontade das partes, considerando a realidade em que celebrado o negócio jurídico, ou seja, na modalidade contratual de adesão. Ademais, há que se ressaltar a vulnerabilidade técnica e informacional, frente ao dever de informação a ser cumprido pela operadora de saúde, que no mais das vezes é violado e não chega a ser efetivado nos termos do artigo $4^{\circ}$, inciso IV do Código de Defesa do Consumidor (1990), o qual consigna a necessidade de "educação e informação de fornecedores e consumidores, quanto aos seus direitos e deveres, com vistas à melhoria do mercado de consumo".

As demandas judiciais, na maioria das vezes, tratam de situações em que os clientes do plano de saúde pleiteiam cobertura e custeio de procedimentos ou eventos de saúde não previstos contratualmente. Acerca do tema, Martins (2015, p. 192), destaca:

Diante dessas situações, ao intérprete aplicador competirá proceder à análise das restrições contratualmente estabelecidas, especialmente em face do direito fundamental à saúde, bem como considerar todo arcabouço normativo infraconstitucional destinado a regulamentar as relações contratuais entre as operadoras de planos privados de assistência à saúde e seus beneficiários, para encontrar uma solução constitucio- 
nalmente adequada para o problema, a qual perpassa peladefinição da extensão da eficácia do direito fundamental à saúde no âmbito desta relação jurídica entre particulares e seus reflexos sobre a autonomia privada e liberdade contratual.

Nesse passo, podemos observar que o cerne da discussão e da ponderaçãoa ser realizada pelo operador do direito que analisará a questão judicializada, diz respeito não ao direito fundamental à saúde - pois incontroverso e superior a todo embate, uma vez que inerente a cada indivíduo -, mas na análise das cláusulas contratuais, que se mostram abusivas na limitação de cobertura de procedimentos médicos, hospitalares ou laboratoriais, sob a ótica do Código de Defesa do Consumidor e de toda a extensão normativa atinente ao tema.

Muito se questiona acerca da atuação do Judiciário no sentido de interferir naliberdade negocial e contratual das operadoras de planos de saúde, bem como na autonomia da vontade de ambas as partes do negócio jurídico, beneficiário e operadora, tendo em vista que o direito fundamental à saúde deve ser viabilizado pormeio de políticas públicas, e que a operadora de saúde suplementar deve ater-se aocumprimento das normas relativas ao tema, cumprindo as exigências delas emanadas, bem como as orientações e determinações oriundas da agência reguladora do setor. Sobre o tema, Schulze (2018, p. 61), pondera:

O papel do Judiciário, neste tipo de processo, é tentar equilibrar dois in-
teresses aparentemente antagônicos, dos consumidores e das operado-
ras de planos de saúde. Vale dizer, a decisão mais adequadanestes casos
é encontrar um ponto que atenda as normas de proteçãoaos usuários e,
ao mesmo tempo, permitir manter o equilíbrio atuarialdas operadoras
de planos de saúde.

Isto posto, verifica-se a impossibilidade de mitigar a judicialização da saúde suplementar, considerando a vulnerabilidade dos beneficiários e a constitucionalização do acesso aos serviços de saúde. A situação como um todo se agrava a partir da insuficiência de informação, além do fato de o consumidor ser a parte leiga na tratativa do negócio jurídico celebrado com a operadora, desconhecendo todos os custos e procedimentos que envolvem a cadeia atuarial da prestadora de serviços, sem contar o desequilíbrio econômico entre as partes.

Constata-se que a decisão de cobertura de procedimentos médicos, hospitalares, laboratoriais ou eventos de saúde, estarão diretamente relacionados com a análise contratual do plano privado de assistência à saúde, com vistas à verificação da ocorrência de eventuais abusividades, ambiguidades ou ilegalidades nas cláusulas contratuais.

\section{GESTÃO DA SAÚDE PRIVADA: BREVE ANÁLISE DA EFICIÊNCIA E QUALIDADE DOS SERVIÇOSPRESTADOS AO CONSUMIDOR}

Diante de todo o cenário narrado, há que se analisar as questões relacionadas à eficiência e à qualidade dos serviços prestados pelas operadoras de planos de 
saúde, sob a ótica contratual e consumerista, sem perder de vista os princípios da saúde suplementar, quais sejam o princípio da defesa do mercado, da defesa do consumidor e, notadamente, o princípio da efetiva tutela da saúde.

Segundo Figueiredo (2012, p. 21), "as normas de direito de saúde suplementar devem nortear a assistência privada à saúde de modo a impor e garantirque os serviços prestados sejam efetivamente capazes de sanar a tempo e prevenir as enfermidades". Vale dizer, o atendimento médico-hospitalar dispensado ao beneficiário do plano de saúde deve primar pela qualidade, a um custo compatível com o produto negociado no contrato de consumo.

A Agência Nacional de Saúde Suplementar - ANS, além de exercer as atividades de controle e fiscalização, também é responsável pelo aprimoramento da qualidade e eficiência do sistema de saúde suplementar. Para tanto, foi implantado um sistema que capta "[...] informações cadastrais, contratuais, financeiras e estatísticas, que tem permitido avanços expressivos com vista à análise qualitativa dosetor, servindo, ao mesmo tempo, como subsídio para o desenvolvimento de planos e estratégias na dimensão qualidade do setor." (VECINA NETO; FIGUEIREDO, 2016,p. 99).

O papel da ANS, como norteador da gestão da saúde suplementar, traz benefícios a todos os atores partícipes da cadeia, vez que promove a transparência de informações, a educação de valores sustentáveis, a parceria público-privado, a promoção à concorrência do mercado privado de saúde, dentre outros. No sítio eletrônico da autarquia é possível acompanhar as ações e campanhas com vistas à promoção de cuidados e promoção à saúde. Dentre eles, destacamos: "Programas de Promoção da Saúde e Prevenção de Riscos e Doenças", seccionado em grupos e área de atuação, tendo como objetivo a mudança do modelo assistencial no sistema de saúde e a melhoria da qualidade de vida dos beneficiários de planos de saúde, considerando a longevidade da população brasileira, a prevalência de parto cesariana, o câncer, a depressão, o diabetes, a hipertensão, a obesidade, o alcoolismo, entre outros.

Com isso, o programa trabalha, junto ao usuário do plano, uma mudança de comportamento social, estimulando hábitos saudáveis, visando uma qualidade de vidamelhor e, por consequência, uma diminuição dos gastos com internações hospitalarese tratamentos de alto custo. Isso não quer dizer que se deve ir menos ao consultório médico. Pelo contrário, o beneficiário do plano de saúde deve consultar seu médico de confiança regularmente, realizar os exames de rotina, a fim de detectar precocemente eventuais doenças. Pode-se afirmar que essas ações promovem, alémda saúde e qualidade de vida, a sustentabilidade do setor de saúde suplementar, como uso racionalizado dos serviços.

Para estimular práticas de gestão com qualidade, a ANS editou a Resolução Normativa ${ }^{\circ}$ 440, de 13 de dezembro de 2018, onde instituiu o Programa deCertificação de Boas Práticas em Atenção à Saúde, visando "incentivar as operadorasde planos de saúde a desenvolverem um cuidado cada vez mais qualificado aos seus beneficiários, através da implantação de redes de atenção ou linhas de cuidado 
certificadas por entidades acreditadoras reconhecidas pela Agência Nacional de Saúde Suplementar (ANS)".

A fim de valorar a prestação de serviços de saúde (hospitais, clínicas, laboratórios e profissionais de saúde), a ANS instituiu o QUALISS - Programa de Qualificação dos Prestadores de Serviços de Saúde, regulamentado pela $\mathrm{RN} \mathrm{n}^{\mathrm{o}}$ 405, de maio de 2016, ao estabelecer atributos de qualidade relevantes para o aprimoramento assistencial oferecido pelos prestadores de serviços, bem como na avaliação da qualificação destes, relacionados à acreditação, segurança do paciente, especialização profissional, monitoramento da qualidade por meio de indicadores, etc.

Outra importante norma é a Resolução Normativa n ${ }^{\circ} 363$, de 11 de dezembro de 2014, que dispõe sobre as regras para celebração dos contratos escritos firmados entre as operadoras de planos de assistência à saúde e os prestadores de serviços de atenção à saúde e dá outras providências.

E, ainda, o "Programa de Acreditação de Operadora", instituído pela Resolução Normativa ${ }^{\circ}$ 452, de 09 de março de 2020, objetiva a promoção da qualidade e sustentabilidade na prestação de serviços e produtos aos beneficiários dasaúde suplementar, através da Gestão Organizacional, Gestão da Rede Prestadora, Gestão em Saúde e Experiência do Beneficiário.

Conforme explanamos na seção pertinente que trata da lei de planos de saúdee da criação da ANS, há um rol de procedimentos e eventos de saúde, que toda operadora de planos privados de assistência à saúde deve, obrigatoriamente, disponibilizar a seus beneficiários, conforme a espécie de plano contratado.

Destacamos que este rol é aplicável aos planos privados de assistência à saúde contratados a partir da vigência da lei de planos de saúde, datada de 02 de janeiro de 1.999, os quais são denominados planos novos.

Os planos antigos, ou seja, aqueles celebrados antes da entrada em vigor dalei de planos de saúde, não são regulados por tal legislação. Entretanto, são fiscalizados pela ANS, cumprindo a ela a verificação da correta aplicação das regras oriundas do instrumento que celebrou o liame entre a operadora e o beneficiário, sem perder de vista a possibilidade de aplicação dos demais instrumentos normativos, anteriormente citados e atinentes ao tema, principalmente as normas oriundas do Código de Defesa do Consumidor.

É conveniente pontuar que a análise acerca da eficiência e da qualidade dos serviços prestados pelas operadoras de planos privados de assistência à saúde é tratada aqui de maneira ampla, a fim de possibilitar ao leitor um panorama geral, nãobuscando em nenhum momento encerrar os debates acerca de um assunto tão vastoe socialmente significativo.

Ademais, este estudo tem como centro a estrutura contratual dos planos privados de assistência à saúde, por adesão, sendo importante esclarecer que as relações oriundas dos liames celebrados entre operadoras e beneficiários devem obedecer aos regramentos contidos no contrato que, regra ética e geral, faz lei entre as partes. A fiscalização dessa relação deve ser levada a efeito pelos órgãos compe- 
tentes, que devem considerar o plano escolhido pelo beneficiário observando se a operadora cumpre com todos os requisitos legais.

Sendo assim, ao verificar eventual ilegalidade supostamente levada a efeito pela operadora do plano privado de assistência à saúde, deve-se ponderar a respeitoda cobertura do plano escolhido pelo beneficiário, somente então podendo-se averiguar eventual irregularidade ou negativa de cobertura indevida, tendo em vista as coberturas obrigatórias e a legislação protetiva dos consumidores.

\section{CONSIDERAÇÕES FINAIS}

O direito à saúde possui estatura constitucional, compõe a personalidade jurídica dos indivíduos, apresenta-se como um direito irrenunciável, fundamental e integrante da dignidade da pessoa humana, inerente a todos os brasileiros, amparados e protegidos pela Carta Magna. Inquestionável, portanto, a sua importância e magnitude, diante do tema tratado neste artigo científico.

Em razão de todo o exposto, podemos observar a importância e a atualidade de tal temática na vivência de muitos brasileiros, que investem na aquisição de planosprivados de assistência à saúde com o intuito de possuírem um maior e melhor respaldo médico, hospitalar e laboratorial para si e para seus familiares.

Neste ponto, não devemos deixar de destacar a importância de o consumidor avaliar pormenorizadamente a modalidade de plano que deseja adquirir, que deve serdetidamente analisado e investigado no momento da contratação, a fim de evitar futuros transtornos, que no mais das vezes resulta em ações judiciais pouco céleres e extremamente desgastantes.

Percebemos, em nossas pesquisas, que o legislador buscou tratar do tema de forma ampla, prevendo o maior número de situações possíveis, mas, quando se trata da realidade humana, é praticamente impossível cumprir tal desígnio, tendo emvista o grande dinamismo e as especificidades que qualificam as relações humanas, circunstância em que a aplicação da Teoria do Diálogo das Fontes mostra-se imperiosa e, por muitas vezes, revela-se como o melhor caminho para a resolução satisfatória das demandas que decorrem das relações aqui analisadas.

A realidade humana, conforme destacamos anteriormente, é dinâmica, e os liames contratuais oriundos dos contratos que abarcam a saúde suplementar geram grande judicialização e, neste cenário, observamos a importância da atuação do Poder Judiciário, do Ministério Público, da Defensoria Pública, da agência reguladorado setor (ANS), bem como o órgão administrativo de defesa dos consumidores, Procon, e a sociedade civil (Idec).

Depreendemos, ademais, a grande necessidade de se propagar aos consumidores, de forma mais acessível e didática, as informações referentes àcontratação dos planos privados de assistência à saúde, medida que claramente nãoresolveria todos os conflitos que decorrem de tal relação contratual, mas que ao nossover, reduziriam consideravelmente as dúvidas e irresignações dos beneficiários,partindo do pressuposto de que, munido do máximo de informações possíveis o pretenso 
beneficiário de um plano privado de assistência à saúde poderá fazer uma escolha mais consciente do serviço que virá a adquirir e poderá realizar de maneira mais efetiva a fiscalização do serviço prestado, a fim de constatar se está de acordo com o avençado.

Por fim, não podemos deixar de mencionar a importância da gestão de qualidade exercida pela Agência Reguladora e pelos organismos de fiscalização, que atuam de forma a garantir a realização do princípio da efetiva tutela da saúde, objetivando que os planos de saúde suplementar observem e cumpram todos os regramentos que incidem em seu campo de atuação, bem como para não perder de vista a realização de sua finalidade e o motivo ensejador de sua aquisição pelos beneficiários, que é a busca por melhor atendimento nas questões concernentes a sua saúde e de seus familiares.

\section{REFERENNCIAS}

AGÊNCIA NACIONAL DE SAÚDE SUPLEMENTAR, seção espaço do Consumidor. Disponível em http://www.ans.gov.br/planos-de-saude-e-operadoras/espaco-do- consumidor/48-planos-de-saude-e-operadoras/espaco-do-consumidor/perguntas- frequentes/781-controle-de-acesso-aos-servicos-de-saude-o-que-o-plano-de-saude- pode-restringir. Acesso em 30/07/2020.

AGÊNCIA NACIONAL DE SAÚDE SUPLEMENTAR. Seção Acreditação de Operadoras. Disponível em http://www.ans.gov.br/planos-de-saude-e-operadoras/informacoes-e-avaliacoes-de- operadoras/acreditacao-de-operadoras. Acesso em 23/11/2020.

_AGÊNCIA NACIONAL DE SAÚDE SUPLEMENTAR. Seção Certificação de Boas Práticas. Disponível em http://www.ans.gov.br/gestao-em-saude/certificacao-de-boas-praticas. Acesso em23/11/2020.

AGÊNCIA NACIONAL DE SAÚDE SUPLEMENTAR. Seção Promoprev. Disponível em http://www.ans.gov.br/gestao-em-saude/promoprev. Acesso em 23/11/2020.

_AGÊNCIA NACIONAL DE SAÚDE SUPLEMENTAR. Seção QUALISS - Programa de Qualificação dos Prestadores de Serviços de Saúde. Disponível em http://www.ans.gov. $\mathrm{br} /$ gestao-em-saude/qualiss- programa-de-qualificacao-dos-prestadores-de-servicos-de-saude-2. Acesso em 23/11/2020.

BARBUGIANI, Luiz Henrique Sormani. Planos de Saúde: Doutrina, Jurisprudência eLegislação. São Paulo: Saraiva, 2015.

BRASIL. Código Civil. Brasília: DF, Senado, 2002.

BRASIL. Código de Defesa do Consumidor. Brasília: DF, Senado, 1990.

BRASIL. Constituição da República Federativa do Brasil: promulgada em 05 deoutubro de 1988. Brasília: DF, Senado, 1988. 
BRASIL. Lei n. 9.656, de 3 de junho de 1998. Dispõe sobre os planos e segurosprivados de assistência à saúde. Disponível em: http://www.planalto.gov.br/ccivil_03/Leis/L9656. htm. Acesso em: 23/11/2020.

BRASIL. Superior Tribunal de Justiça. Agravo Regimental no Agravo em Recurso Especial n ${ }^{0}$ 295.133/SP. Relator: Ministro Raul Araújo. Disponível em https://stj.jusbrasil. com.br/jurisprudencia/23888417/agravo-regimental-no-agravo-em- recurso-especial-agrg-no-aresp-295133-sp-2013-0033443-9-stj/inteiro-teor- 23888418?ref=juris-tabs. Acesso em 03/07/2020.

BRASIL. Superior Tribunal de Justiça. Recurso Especial $\mathbf{n}^{\circ}$ 1.739.907/DF. Relatora: Ministra Nancy Andrighi. Disponível em

https:/ / scon.stj.jus.br/SCON/GetInteiroTeorDoAcordao?num_registro=202000035781 \&dt_publicacao=09/09/2020. Acesso em 07/12/2020.

BRASIL. Superior Tribunal de Justiça. Recurso Especial no $\mathbf{n}^{\mathbf{0}} \mathbf{8 7 1 . 3 2 6 / R S}$. Relatora: Ministra Nancy Andrighi. Disponível em

https://processo.stj.jus.br/processo/revista/documento/mediado/?componente=ITA\&s equencial $=1969084 \&$ num_registro $=201801081674 \&$ data $=20200826 \&$ formato $=$ PDF. Acesso em $07 / 12 / 2020$.

DINIZ, Maria Helena. Curso de Direito Civil Brasileiro, volume 3: Teoria dasObrigações Contratuais e Extracontratuais. São Paulo: Saraiva, 2014.

FABRETTI, Fernanda Massad de Aguiar. Judicialização da Saúde: a visão do poder executivo. Coordenado por BUCCI, Maria Paula Dallari e DUARTE, ClariceSeixas. São Paulo: Saraiva, 2017.

FIGUEIREDO, Leonardo Vizeu. Curso de Direito de saúde Suplementar: ManualJurídico de Planos e Seguros de Saúde. 2. ed. rev., atual. e ampl. Rio de Janeiro: Forense, 2012

GOMES, Josiane Araújo. Contratos de Planos de Saúde. A busca judicial pelo equilíbrio de interesses entre os usuários e as operadoras de planos de saúde. Leme (SP): JH Mizuno, 2016.

GREGORI, Maria Stella. Planos de Saúde: a ótica da proteção do consumidor. 4.ed. rev., atual. e ampl. São Paulo: Thomson Reuters Brasil, 2019.

MARQUES, Claudia Lima. Contratos no Código de Defesa do Consumidor: o novo regime das relações contratuais. 8. ed. rev., atual. e ampl. São Paulo: EditoraRevista dos Tribunais, 2016.

MARTINS, Thiago Penido. Contratos de planos de saúde: o direito à saúde nasrelações jurídicas entre as operadoras de planos de assistência à saúde e seus beneficiários. Curitiba: Juruá, 2016.

SCAFF, Fernando Campos. Direito à saúde no âmbito privado: planos deadesão, planos de saúde e seguro saúde. São Paulo: Saraiva, 2010. 
SCHULZE, Clenio Jair. Judicialização da saúde no século XXI. Porto Alegre:Verbo Jurídico, 2018.

SILVA, José Afonso da. Curso de Direito Constitucional Positivo. 43. ed. rev. eatual. até a Emenda Constitucional n. 105, de 12.12.2019. São Paulo: Malheiros, 2020.

SILVEIRA, Karyna Rocha Mendes da. Doença Preexistente nos Planos de Saúde. São Paulo: Saraiva, 2009.

VECINA NETO, Gonzalo; FIGUEIREDO, Luiz Fernando. Estrutura dos Serviços Privados de Saúde no Brasil. In: VECINA NETO, Gonzalo; MALIK, Ana Maria. Gestão em Saúde. 2. ed. Rio de Janeiro: Guanabara Koogan, 2016. cap. 6, p. 99 